\title{
O universo de Clara Crocodilo ${ }^{1}$
}

\author{
Luiz Nazario ${ }^{2}$
}

Um adolescente sensível quer provar ao mundo feminino, através de uma obra, que tem valor social. Nostálgico das tradições, leitor de Jorge Amado, estava destinado a ser um novo Chico Buarque de Holanda um compositor querido das famílias. Mas algo nele fracassa. É sincero, mas triste, o amor que dedica aos criadores populares. Quando faz treze anos, a televisão chega à sua cidade, Londrina, no Paraná. Para crescer, muda-se para São Paulo: sua infância é tragada pela história. É quando começa a perder o equilíbrio. Inventa happenings onde combina música e teatro em espetáculos "sem significado". Os populistas observam-no desde Londrina. Eles se reúnem em fossas e fabricam diagnósticos: é um indivíduo; um cabeça-dura atrasado; uma criança doente do comunismo. E, contudo, há casos de crianças saudáveis que param de comer porque não suportam a atrocidade do que existe e não quer perecer. Num romance de Günther Grass, a única reação que uma criança pode oferecer à loucura dos adultos é parar de crescer. Arrigo Barnabé para de cantar. Ele diz por que numa impressionante canção: "Está acontecendo tanta coisa... Eu não consigo mais cantar”. Ali onde canta, não é com sua voz. A revolta do corpo, que rejeita ser apropriado pelo conglomerado, desativando uma função natural "necessária", é a primeira manifestação de uma humanidade decidida a resistir ao horror. Nasceu para devastar aquele amor que não tem correspondência. Perdendo o seu muito cedo, Arrigo não encontrou outro. É esse no man's land que sua obra vai ocupar.

Os guardiões da cultura popular, armados de tacapes e flechas, zelam para que o "inimigo" não se aproxime do templo. Em vão: Arrigo profana o santuário, despertando-nos para a massificação que invalida os conceitos pelos quais se podia pensar como um populista. $O$ pensamento mágico tende a confundir o visto com o visor, culpando o visionário pela catástrofe que, de sua posição privilegiada, pode ver ou

1 Originalmente publicado em: NAZARIO, Luiz. Da natureza dos monstros. São Paulo: Editora do Autor, 1983, p. 29-34. O ensaio não foi retomado na reedição ampliada do livro, publicada em 1998 pela Editora Arte \& Ciência.

2 Professor Associado IV da Universidade Federal de Minas Gerais (UFMG, Belo Horizonte, MG, Brasil). Bolsista em Produtividade em Pesquisa do CNPq - Nível ıD. E-mail: luiz.nazario@terra.com.br 
prever. Nesse sentido, a música de Arrigo apenas parece agressiva: de fato, limita-se a tornar transparente a agressividade da realidade que emoldura - o processo de industrialização total por que passa a América Latina: internacionalizada e urbanizada em seus pontos nevrálgicos, ela só pode manter o ritmo de crescimento sobre a ruína de suas tradições. $\mathrm{O}$ sonho agrário do populismo é desfeito pela realidade tecnológica, como um castelinho de areia que se dissolve, engolido pela onda. As novas gerações são formadas por mutantes, que tentam sobreviver arrastandose do centro para a margem, da cultura para a natureza. A hipocrisia do humanismo burguês não resiste à nova mentalidade infantil, moldada pela televisão. A reposta mais imediata a esse humanismo é a contracultura, movimento negativo que usa reiteradamente a metáfora do crime gratuito para falar da liberdade. Para essa vanguarda sem tradição, o herói é o arquicriminoso que viola as leis não por necessidade, mas por prazer. O crime gratuito é sinal do mau instinto, da sede de vingança, da perversão sexual: do lado sombrio do homem, negado sem sucesso pelas correntes otimistas do pensamento. Aquilo que o conglomerado não consegue controlar torna-se, para a contracultura, o símbolo da afirmação do homem. Do arquicriminoso para o monstro há apenas um passo. De vítima total a carrasco total, o monstro libertador investe contra um conglomerado que integra até os deficientes físicos - os "monstros" naturais que permaneciam, por sua condição, afastados da produção. Para a contracultura, a saída está na droga, no sexo, no crime, na loucura, na exaltação do lixo, do grotesco, do glamour e da decadência, na monstruosidade positivamente afirmada. O que o liberalismo oferecia como liberação não passava de barbárie: à cópia falsificada da selva a contracultura prefere a selva original. A decisão posta entre a escolha do mal maior e do mal menor elimina a esperança de uma nova qualidade de vida. A revolta deformada de hoje tenta realizar o bem fazendo renascer a selva natural dentro da selva artificial. A tentativa parece tão destinada ao fracasso quanto o cuidado com que a dona de casa ajeita vasos de planta na varanda do vigésimo andar de seu apartamento.

A afirmação de Herbert Marcuse de que a civilização entrou numa fase sadomasoquista global encontra imediata confirmação numa revista especializada em crimes horrendos, intitulada Eros. O homem "normal" não distingue mais o prazer do sofrimento. Mesmo o sórdido romantismo do tipo "nós dois contra o mundo louco" desapareceu: a subcultura de massa não celebra mais o casal. O mundo louco invadiu o doce lar, impondo a nova moral da promiscuidade.

Cúmplices da ordem mutiladora, os poderes que oferecem alívio para a dor são os mesmos que a prolongam pela prévia supressão da 
cura. Na necessidade cada vez maior de criar-se um bem-estar isolado do mal-estar geral, a infelicidade crônica da civilização obtém, no desejo de felicidade dos indivíduos, a melhor garantia de sua expansão.

A mais perceptível característica da moderna engrenagem social é a velocidade com que transforma os que se deixam morder e engolir. $O$ frenesi das mutações monstruosas não concede o tempo de reflexão em que a afetividade e a crítica se desenvolvem. O resultado é a brutalidade e a indiferença de todos em relação a todos. $O$ silêncio e a calma desaparecem e, em seguida, a ternura e o desejo: tudo é som e fúria nas metrópoles.

Nos melhores momentos de sua música, Arrigo Barnabé domina as forças que subjugam o homem: o entendimento da história é obnubliado pelas fragmentações das palavras cujas sílabas são distribuídas nas linhas melódicas (quase sempre atonais) - o que nos leva a ouvir outra vez cada composição e a evoluir com ela do estranhamento ao escândalo; o enlevo do corpo é impedido pelas fragmentações do ritmo por alternância de compassos desiguais - os selvagens do auditório tentam em vão dançar essa música para afastar os maus espíritos; a consciência feliz é ofuscada pelas fragmentações das próprias personagens em permanente mutação - em Clara Crocodilo, um office-boy transforma-se em um assassino; sua ex-namorada transforma-se numa chacrete; em Infortúnio, uma viúva, arrasada com a morte do marido, transforma-se numa prostituta; em Diversões eletrônicas, um maníaco de autorama transforma-se num corredor que agride a amante que, à noite, transforma-se na agressora de um vadio; em Orgasmo total, uma mulher, depois de transformar-se, no escuro, em um animal, oferece-se como refeição.

De vítima a carrasco: esse é o movimento básico das personagens de Arrigo Barnabé. E se possuir uma mulher é ascender à condição de adulto, adquirindo um "saber" biológico, inefável, a integração aí equivale a uma desintegração: as mulheres de suas canções são, ao mesmo tempo, objetos de desejo e símbolos de morte, servindo de intermediárias entre os coitadinhos e o sistema de perdição. Nesse universo, o tempo leva à destruição e à morte: não é o tempo hegeliano - deus onisciente $\mathrm{e}$ benigno, que conduz a dialética histórica a um happy-end, mas o tempo sartriano - deus cego e maligno, que devora os existentes e só lhes deixa uma chance, para dizer sim ou não. Se a maioria diz sim, Clara Crocodilo diz não. Também uma vítima, que um laboratório psicodélico atrai e transforma em monstro, metade-homem, metade-jacaré, Clara sofre uma mutação radical, que não o torna uma vítima comum, mas uma vítima total. E é a parte de consciência que conserva que faz com que 
ele se revolte. A revolta não o torna, igualmente, um carrasco comum, mas um carrasco total. Sua fúria não tem objeto: é todo o conglomerado que ele ameaça. Criminoso absurdo, que as balas não penetram e que se enfurece dia-a-dia, até libertar-se das grades - do reino da necessidade - Clara Crocodilo desperta para dedicar-se full-time à violência, realizando, de dentro para fora, a destruição da sociedade.

Liberando a fantasia de dominação das massas, historicamente dominadas, o conglomerado legalizou as forças acumuladas da paranóia. Aí, o desviante e o normal, o irracional e o racional fundem-se numa mesma dimensão. Nenhuma imaginação supera em delírio a própria realidade, tornada Surrealidade. Agora, a arte só mantém seu poder de negação onde e quando se faz dissonante e harmônica, deformante e composta, desfigurante e concreta. Mesmo o Surrealismo foi recuperado: "A psicanálise foi aplicada às public relations e à human engineering: o universo onírico do Surrealismo, com todos os seus clamorosos elementos sexuais, foi posto a serviço da publicidade e transferidos para os filmes de terror e para não poucos temas de ficção-científica. Por fim, a prática do brain-storming - isto é, das reuniões em que cada um fala sem controle crítico, favorecidas por uma espécie de impudência coletiva do pensamento, com o fim de fornecer material à publicidade - parece uma paródia das sessões da primeira central surrealista", constatou Franco Fortini.

Arrigo Barnabé rasga, então, o véu da imaginação, para oferecer a realidade em fotomontagens, instantâneos, reportagens, crônicas, fragmentos da surrealidade impressa no cotidiano. E basta ouvir essa estrofe:

\section{Ela era caixa num supermercado}

Todo dia ela só apertava os botões

E aquelas máquinas cantavam.

para que o sentido da alienação universal penetre em nós como uma faca. Nenhuma promessa pode exorcizar o mal-estar do presente quando a arte consegue ser apocalíptica limitando-se a enunciar o que existe em cada esquina.

Programas de auditório, supermercados, clínicas, presídios, fliperamas, motéis, cemitérios, bares, restaurantes, escritórios, discotecas e drive-in's são os espaços abertos e confundidos no conglomerado pelo novo estilo de vida. Esse estilo de vida engloba e facilita o movimento e a mutilação do corpo, a pacificação e a agressividade do espírito, o prazer instantâneo e a frustração que perdura; a boa vida que se tem de 
viver entre o lixo e a diversão, o abandono e a gargalhada, a histeria e a entrega, a miséria e o desperdício, o conforto e a radioatividade; como se nada estivesse acontecendo.

E é outro verso de Arrigo que capta, inconscientemente, tudo que está acontecendo:

\section{Você nunca imaginou \\ Mas eu vi \\ No luminoso estava escrito \\ Diversões eletrônicas.}

Estávamos acostumados ao que nos cerca: Arrigo recupera nossa memória: essa realidade não existia ontem - foi gerada, lentamente, pela imaginação. Não por uma imaginação humana. Essa realidade - pois é preciso assentir que o que existe é real - foi materialmente produzida pela imaginação mecânica, inconsciente, das massas. Estamos mergulhados na fantasia programada desse cérebro monstruoso e determinado que multiplica suas formas e combinações, às quais devemos nos adaptar como personagens de sonho - sem presença real; sem poder transformar a matéria com nossas mãos; sem noção precisa de tempo e espaço; sem acrescentar, a cada dia que passa, nada ao nada de nossas vidas. E quando olhamos para um anúncio de fliperama - "gente divertindo gente" - não nos surpreendemos. Divertimos a máquina, enchendo seu vazio de níqueis, e a máquina nos diverte, enchendo nosso vazio de imagens. Imagens de onipotência de nossos torpedos naufragando o submarino do inimigo, de nossas bolas entrando no maior número de buracos - em todos os símbolos de nossos órgãos sexuais humilhados e instrumentalizados para fazer render os indivíduos atomizados. Mas o processo continua: a máquina ensina-nos a maquinar nosso corpo e nosso corpo, maquinado, ensina outro corpo a maquinar. A iniciação se completa quando a máquina se acopla ao nosso corpo para não mais se desgarrar, devorando pouco a pouco a raiz de nossa humanidade. Trocamos de papel com nossas máquinas: enquanto trabalhamos, elas cantam.

DOI: http://dx.doi.org/10.11606/issn.2316-901X.v0i59p413-418 
